\title{
Mycotrienin II, a translation inhibitor that prevents ICAM-1 expression induced by pro-inflammatory cytokines
}

\begin{abstract}
Yuriko Yamada $^{1}$, Etsu Tashiro ${ }^{2}$, Shigeru Taketani ${ }^{1}$, Masaya Imoto $^{2}$ and Takao Kataoka ${ }^{1}$
Pro-inflammatory cytokines, such as tumor necrosis factor (TNF)- $\alpha$ and interleukin- $1 \alpha$ (IL-1 $\alpha$ ), trigger the activation of the transcription factor nuclear factor-кB, a molecule that induces the expression of a variety of genes, including intercellular adhesion molecule-1 (ICAM-1). Here, we report that mycotrienin II, a member of the triene-ansamycin group, inhibited the cell-surface ICAM-1 expression induced by TNF- $\alpha$ more strongly than that induced by IL-1 $\alpha$ in human lung carcinoma A549 cells. Mycotrienin II was found to inhibit protein synthesis in intact living cells, as well as in cell-free translation systems. Among translation inhibitors tested, acetoxycycloheximide and anisomycin, but neither puromycin nor emetine, inhibited the TNF- $\alpha$-induced ICAM-1 expression at lower concentrations than the IL-1 $\alpha$-induced ICAM- 1 expression. Several compounds of the triene-ansamycin group (that is, mycotrienin I, trienomycin A, trierixin, quinotrierixin and quinotrierixin HQ) also inhibited ICAM-1 expression, as well as cell-free translation in a manner similar to mycotrienin II. These results indicate that mycotrienin II is a direct inhibitor of translation, thereby inhibiting ICAM-1 expression induced by pro-inflammatory cytokines.
\end{abstract} The Journal of Antibiotics (2011) 64, 361-366; doi:10.1038/ja.2011.23; published online 30 March 2011

Keywords: ICAM-1; IL- $1 \alpha$; mycotrienin II; NF- $\kappa$ B; pro-inflammatory cytokine; TNF- $\alpha$; triene-ansamycin

\section{INTRODUCTION}

Pro-inflammatory cytokines, such as tumor necrosis factor (TNF)- $\alpha$ and interleukin- $1 \alpha$ (IL- $1 \alpha)$, induce the expression of a variety of genes essential for inflammatory responses, such as intercellular adhesion molecule-1 (ICAM-1; CD54). ${ }^{1}$ ICAM-1 is a cell-surface glycoprotein that binds to lymphocyte function-associated antigen-1 (CD1la/ $\mathrm{CD} 18)$ and Mac-1 (CD11b/CD18). ${ }^{2}$ As one of its physiological roles, ICAM-1 inducibly expressed on vascular endothelial cells is required for the recruitment of leukocytes via the interaction with lymphocyte function-associated antigen-1 or Mac-1 and their subsequent transmigration to inflamed sites. ${ }^{3,4}$ ICAM-1 expression is known to be induced primarily by the transcription factor nuclear factor- $\mathrm{\kappa B} .{ }^{1}$ So far, many small molecules targeting the nuclear factor$\mathrm{KB}$ signaling pathway induced by pro-inflammatory cytokines have been identified. ${ }^{5}$

Mycotrienin II (Figure 1a) was isolated from Streptomyces sp. and belongs to the triene-ansamycin group of compounds. ${ }^{6,7}$ Mycotrienin II possesses various biological activities in mammalian cells, such as cytotoxicity and inhibition of osteoclastic bone resorption and endoplasmic reticulum (ER) stress-induced X-box binding protein 1 activation. ${ }^{8-13}$ In the course of our screening for anti-inflammatory agents, we found that mycotrienin II inhibits ICAM-1 expression induced by TNF- $\alpha$ and IL- $1 \alpha$. In this study, we further investigated the molecular mechanism underlying the inhibition of ICAM-1 expression by mycotrienin II.

\section{MATERIALS AND METHODS}

Cell culture

Human lung carcinoma A549 cells were provided by the Health Science Research Resources Bank (Tokyo, Japan). A549 cells were maintained in RPMI 1640 medium (Invitrogen, Carlsbad, CA, USA) supplemented with $10 \%(\mathrm{v} / \mathrm{v})$ heat-inactivated fetal calf serum (JRH Biosciences, Lenexa, KS, USA) and penicillin-streptomycin mixed solution (Nacalai Tesque, Kyoto, Japan).

\begin{abstract}
Reagents
Recombinant human TNF- $\alpha$ and human IL- $1 \alpha$ were kindly provided by Dainippon Pharmaceutical (Osaka, Japan). Mycotrienin I, mycotrienin II, trienomycin A, trierixin and quinotrierixin were isolated from the culture broth of Streptomyces sp. PAE37. ${ }^{13}$ Quinotrierixin HQ, 13-ketomycotrienin I and 13-ketomycotrienin II were prepared as described previously. ${ }^{13}$ Acetoxycycloheximide was isolated from the culture broth of an unidentified actinomycete strain designated by ML44-113F2. ${ }^{14}$ Anisomycin and cycloheximide were purchased from Wako Pure Chemical Industries (Osaka, Japan). Emetine and puromycin were obtained from Sigma-Aldrich (St Louis, MO, USA).
\end{abstract}

${ }^{1}$ Department of Applied Biology, Kyoto Institute of Technology, Matsugasaki, Sakyo-ku, Kyoto, Japan and ${ }^{2}$ Department of Biosciences and Informatics, Faculty of Science and Technology, Keio University, Yokohama, Japan

Correspondence: Dr T Kataoka, Department of Applied Biology, Kyoto Institute of Technology, Matsugasaki, Kyoto 606-8585, Japan.

E-mail: takao.kataoka@kit.ac.jp

Received 3 December 2010; revised 14 February 2011; accepted 17 February 2011; published online 30 March 2011 

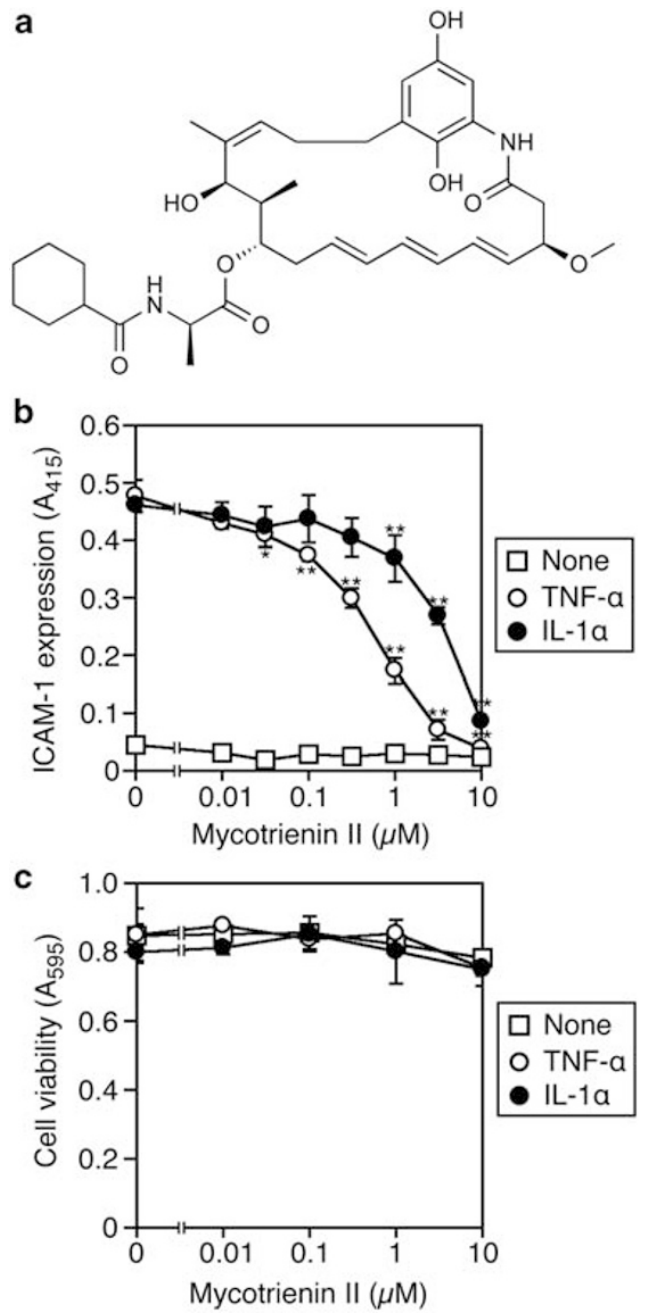

Figure 1 Mycotrienin II inhibits cell-surface intercellular adhesion molecule1 (ICAM-1) expression induced by tumor necrosis factor- $\alpha$ (TNF- $\alpha$ ) and interleukin- $1 \alpha$ (IL-1 $\alpha$ ). (a) Structure of mycotrienin II. (b) A549 cells were pretreated with various concentrations of mycotrienin $\mathrm{II}$ for $1 \mathrm{~h}$ and then incubated with TNF- $\alpha\left(2.5 \mathrm{ng} \mathrm{ml}^{-1}\right.$; open circles) or IL-1 $\alpha\left(0.25 \mathrm{ng} \mathrm{ml}^{-1}\right.$; filled circles) or without cytokines (open squares) for $6 \mathrm{~h}$ in the presence of mycotrienin II. ICAM-1 expression $\left(A_{415}\right)$ is shown as means \pm s.d. $(n=3)$. ${ }^{*} P<0.05$ and ${ }^{* *} P<0.01$, compared with control. Data are representative of two independent experiments. (c) A549 cells were incubated with various concentrations of mycotrienin $\mathrm{II}$ for $1 \mathrm{~h}$ and then incubated with TNF- $\alpha$ (2.5 $\mathrm{ng} \mathrm{ml}^{-1}$; open circles) or IL-1 $\alpha\left(0.25 \mathrm{ng} \mathrm{ml}^{-1}\right.$; filled circles) or without cytokines (open squares) for $6 \mathrm{~h}$ in the presence of mycotrienin II. Cell viability $\left(A_{595}\right)$ is shown as means \pm s.d. $(n=3)$. ${ }^{*} P<0.05$ and ${ }^{* *} P<0.01$, compared with control. Data are representative of two independent experiments.

\section{Assay for cell-surface expression of ICAM-1}

A549 cells were washed twice with phosphate-buffered saline (PBS) and fixed with $1 \%$ paraformaldehyde-PBS for $15 \mathrm{~min}$. After washing twice with PBS, the cells were incubated with $1 \%$ bovine serum albumin (Sigma-Aldrich)-PBS overnight. Fixed cells were treated with mouse anti-human ICAM-1 IgG antibody (clone 15.2; Leinco Technologies, St Louis, MO, USA) for $60 \mathrm{~min}$ and then washed three times with $0.02 \%$ Tween $20-\mathrm{PBS}$. The cells were further treated with horseradish peroxidase-linked anti-mouse IgG antibody (Jackson Immunoresearch, West Grove, PA, USA) for $60 \mathrm{~min}$ and then washed three times with $0.02 \%$ Tween-20-PBS. To develop the colorimetric reaction, the cells were incubated with the substrate solution $(0.2 \mathrm{M}$ sodium citrate ( $\mathrm{pH} 5.3$ ),
$0.1 \%$ o-phenylenediamine dihydrochloride, $0.02 \% \mathrm{H}_{2} \mathrm{O}_{2}$ ) for $20 \mathrm{~min}$ at $37^{\circ} \mathrm{C}$. Absorbance at $415 \mathrm{~nm}$ was measured with a Model 680 microplate reader (Bio-Rad Laboratories, Hercules, CA, USA).

\section{Assay for cell viability}

A549 cells were pulsed with MTT (3-(4,5-dimethylthiazol-2-yl)-2,5diphenyltetrazolium bromide, $500 \mu \mathrm{g} \mathrm{ml}^{-1}$ ) for $4 \mathrm{~h}$ and resultant MTT formazan was solubilized with $5 \%$ sodium dodecyl sulfate overnight. Absorbance at $595 \mathrm{~nm}$ was measured with a Model 680 microplate reader (Bio-Rad Laboratories).

\section{Assay for macromolecular synthesis}

A549 cells were pulse-labeled with $\left[4,5-{ }^{3} \mathrm{H}\right] \mathrm{L}$-leucine $\left(41.66 \mathrm{TBq} \mathrm{mmol}^{-1}\right.$; Moravek Biochemicals, Brea, CA, USA), [methyl- $\left.{ }^{3} \mathrm{H}\right]$ thymidine (2.37 TBq $\mathrm{mmol}^{-1}$; MP Biomedicals, Santa Ana, CA, USA), and $\left[5-{ }^{3} \mathrm{H}\right]$ uridine $\left(0.626 \mathrm{TBq} \mathrm{mmol}^{-1}\right.$; Moravek Biomedicals) for the indicated times. The labeled cells were washed three times with PBS and then lysed with $250 \mathrm{~mm} \mathrm{NaOH}$ for $15 \mathrm{~min}$, followed by $1 \mathrm{~h}$ incubation on ice in the presence of $5 \%$ trichloroacetic acid. The precipitates and the supernatants were separated by centrifugation $(10000 \times g, 5 \mathrm{~min})$. Radioactivity was measured with a 1900CA TRI-CARB liquid scintillation analyzer (Packard Instrument, Meriden, CT, USA).

\section{Assay for cell-free protein synthesis}

The T7-driven luciferase cDNA was subjected to the cell-free reaction $\left(30^{\circ} \mathrm{C}\right.$, $90 \mathrm{~min}$ ) for transcription and translation by the TnT T7 Coupled Reticulocyte Lysate Systems (Promega, Madison, WI, USA). Luciferase mRNA was subjected to the cell-free reaction $\left(30^{\circ} \mathrm{C}, 90 \mathrm{~min}\right)$ for translation by the Rabbit Reticulocyte Lysate System (Promega). Reaction mixtures were mixed with the luciferase assay solution and relative light units were immediately measured with a Lumitester K-100 Luminometer (Hamamatsu Photonics, Hamamatsu, Japan).

\section{Statistical analysis}

Statistical significance was assessed by one-way analysis of variance, followed by the Tuker test for multiple comparisons using KaleidaGraph (Synergy Software, Reading, PA, USA). Differences of $P<0.05$ were considered to be statistically significant.

\section{RESULTS}

\section{Mycotrienin II inhibits cell-surface ICAM-1 expression induced} by TNF- $\alpha$ and IL-1 $\alpha$

Pro-inflammatory cytokines, such as TNF- $\alpha$ or IL- $1 \alpha$, induce the expression of various cell-surface molecules during inflammatory responses. ${ }^{1}$ Upon stimulation with TNF- $\alpha$ or IL- $1 \alpha$, lung carcinoma A549 cells expressed ICAM-1 on their cell surface. Mycotrienin II was found to inhibit the cell-surface ICAM-1 expression induced by TNF- $\alpha$ and IL- $1 \alpha$ in a dose-dependent manner (Figure 1b). As its characteristic inhibitory profiles, the TNF- $\alpha$-induced ICAM- 1 expression ( $\mathrm{IC}_{50}$ value: $0.3 \mu \mathrm{M}$ ) was more strongly inhibited by mycotrienin II than the IL- $1 \alpha$-induced ICAM-1 expression ( IC $_{50}$ value: $3.1 \mu \mathrm{M}$ ). During the same incubation time, mycotrienin II exerted a marginal effect on cell viability up to $10 \mu \mathrm{M}$ even in the presence of TNF- $\alpha$ or IL- $1 \alpha$ (Figure 1c). Consistent with these data, mycotrienin II did not induce the release of L-lactose dehydrogenase into the culture medium in the presence or absence of TNF- $\alpha$ or IL- $1 \alpha$ (data not shown). These results indicate that the inhibition of cell-surface ICAM-1 expression by mycotrienin II is not likely to be nonspecific cytotoxicity and induction of cell death.

\section{Mycotrienin II inhibits cellular and cell-free translation}

Recently, it has been shown by us and other group that the trineansamycin group compounds, such as cytotrienin A and quinotrierixin, are translation inhibitors. ${ }^{15,16}$ To investigate whether mycotrienin 
II selectively affects de novo protein synthesis at the cellular level, A549 cells were pretreated with mycotrienin II and then pulse-labeled with $\left[{ }^{3} \mathrm{H}\right] \mathrm{L}$-leucine, $\left[{ }^{3} \mathrm{H}\right]$ thymidine, and $\left[{ }^{3} \mathrm{H}\right]$ uridine in the presence of the compound. Then, the amount of radioactivity incorporated into the acid-insoluble (macromolecular) fractions was measured. Mycotrienin II inhibited the incorporation of $\left[{ }^{3} \mathrm{H}\right] \mathrm{L}$-leucine in a dose-dependent manner and at the $\mathrm{IC}_{50}$ value of $0.058 \mu \mathrm{m}$ (Figure 2a), whereas mycotriein II did not obviously affect the incorporation of $\left[{ }^{3} \mathrm{H}\right]$ thymidine and $\left[{ }^{3} \mathrm{H}\right]$ uridine (Figure $2 \mathrm{~b}$ ). When $\left[{ }^{3} \mathrm{H}\right] \mathrm{L}$-leucine-labeled cell lysates were separated into acid-soluble supernatants and acid-insoluble precipitates, mycotrienin II inhibited the incorporation of radioactivity into the precipitates, but conversely increased the radioactivity incorporation into the supernatants (Figure 2c). Thus, these results suggest that mycotrienin II does not affect the uptake of amino acids across the plasma membrane, but directly prevents translation.

To further investigate whether mycotrienin II directly affects translation, luciferase cDNA or luciferase mRNA was used as a template for transcription and translation in cell-free systems, based on rabbit reticulocyte lysates. The resultant luciferase activity associated with the protein products was measured. Mycotrienin II suppressed the luciferase activity in the cell-free transcription-coupled translation system ( $\mathrm{IC}_{50}$ value: $5.5 \mu \mathrm{M}$ ) (Figure $2 \mathrm{~d}$ ) and the cell-free translation system ( $\mathrm{IC}_{50}$ value: $4.1 \mu \mathrm{M}$ ) (Table 1 ) at equivalent concentrations. These results indicate that mycotrienin II directly prevents translation.

The triene-ansamycin group of compounds inhibits TNF- $\alpha /$ IL-1 $\alpha-$ induced ICAM-1 expression and translation

To obtain additional evidence that the inhibition of ICAM-1 expression by mycotrienin II is primarily caused by the prevention of translation, the structure-activity relationship of the triene-ansamycin group of compounds (Figure 3) was investigated. In the inhibitory profiles similar to that of mycotrienin II (Figure 1b), mycotrienin I, trienomycin $\mathrm{A}$, trierixin, quinotrierixin and quinotrierixin $\mathrm{HQ}$ inhibited the TNF- $\alpha$-induced ICAM-1 expression more preferentially than the IL- $1 \alpha$-induced ICAM- 1 expression, whereas 13 -ketomycotrienin I, 13-ketomycotrienin II and demethyltrienomycinol were totally inactive up to $10 \mu \mathrm{M}$ (Table 1). Consistent with these data, mycotrienin I, trienomycin A, trierixin, quinotrierixin and quinotrierixin $\mathrm{HQ}$
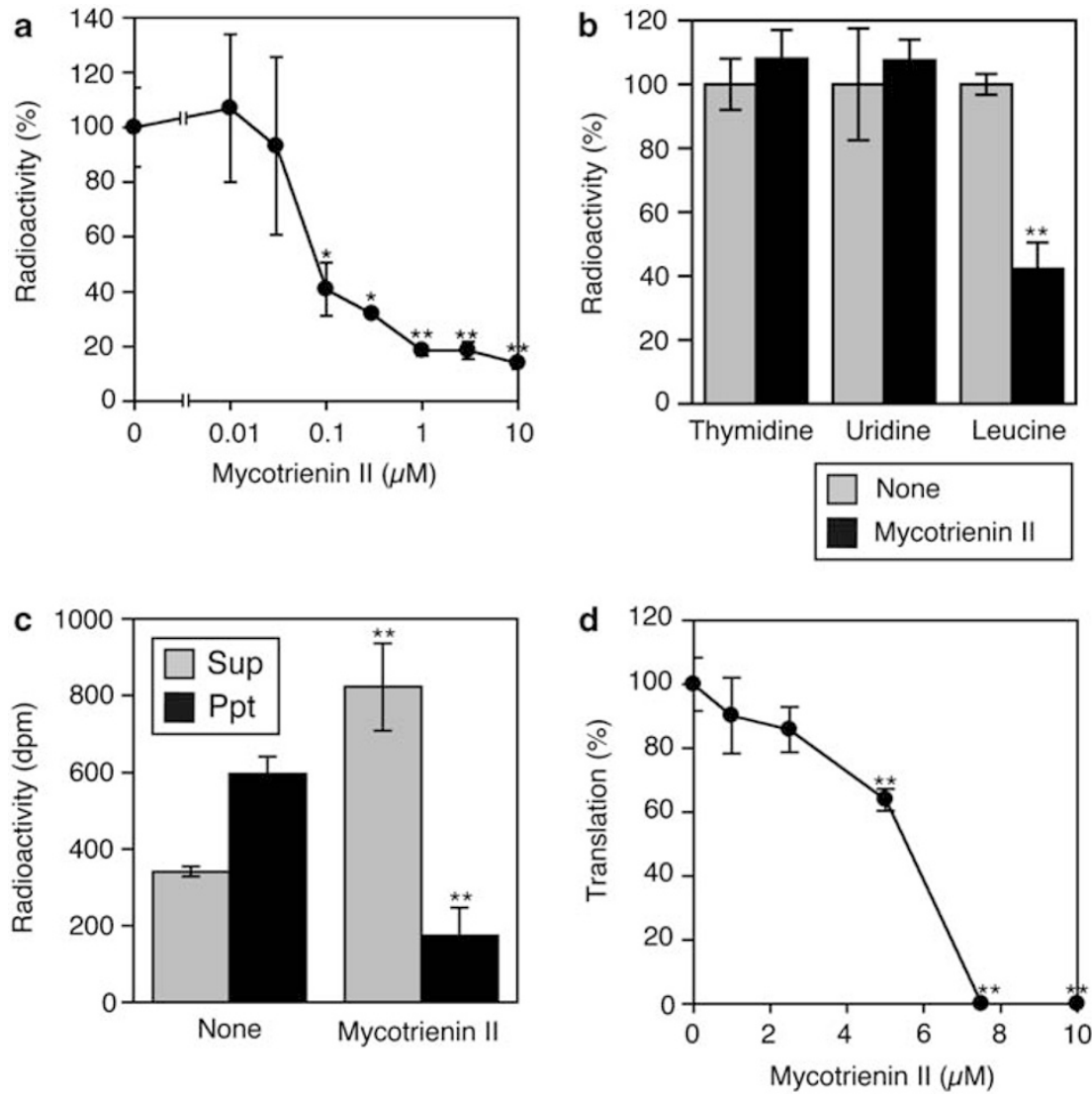

Figure 2 Mycotrienin II directly inhibits de novo protein synthesis. (a) A549 cells were pretreated with various concentrations of mycotrienin II for $1 \mathrm{~h}$ and pulse-labeled with $\left[{ }^{3} \mathrm{H}\right] \mathrm{L}-$ leucine for $2 \mathrm{~h}$ in the presence or absence of mycotrienin II. Radioactivity incorporated into the acid-insoluble fractions was measured. Radioactivity $(\%)$ is shown as means \pm s.d. $(n=3) .{ }^{*} P<0.05$ and ${ }^{* *} P<0.01$, compared with control. Data are representative of two independent experiments. (b) A549 cells were pretreated with (black bars) or without (gray bars) mycotrienin II (1 $\mu \mathrm{M})$ for 30 min and then pulse-labeled with $\left[{ }^{3} \mathrm{H}\right]$ thymidine, $\left[{ }^{3} \mathrm{H}\right]$ uridine or $\left[{ }^{3} \mathrm{H}\right] \mathrm{L}$-leucine for $1 \mathrm{~h}$ in the presence or absence of mycotrienin II. Radioactivity incorporated into the acid-insoluble fractions was measured. Radioactivity (\%) is shown as means \pm s.d. $(n=3)$. ${ }^{*} P<0.05$ and ${ }^{* *} P<0.01$, compared with control. Data are representative of two independent experiments. (c) A549 cells were pretreated with or without mycotrienin II (1 $\mu \mathrm{m})$ for $1 \mathrm{~h}$ and then pulse-labeled with $\left.{ }^{3} \mathrm{H}\right] \mathrm{L}-\mathrm{leucine}$ for $2 \mathrm{~h}$ in the presence or absence of mycotrienin II. Acid-soluble fractions as supernatants (Sup; gray bars) and acid-insoluble fractions as precipitates (Ppt; filled bars) were collected and measured for radioactivity. Radioactivity $(\mathrm{dpm})$ is shown as means \pm s.d. $(n=3)$. ${ }^{*} P<0.05$ and $* * P<0.01$, compared with control. Data are representative of two independent experiments. (d) Luciferase CDNA was transcribed and then translated by rabbit reticulocyte lysates in the presence of various concentrations of mycotrienin II. Luciferase activity (\%) is shown as means \pm s.d. ( $n=3$ ). ${ }^{*} P<0.05$ and ${ }^{* *} P<0.01$, compared with control. Data are representative of two independent experiments. 
inhibited the cell-free translation at comparable concentrations, whereas 13-ketomycotrienin I, 13-ketomycotrienin II and demethyltrienomycinol were inert up to $10 \mu \mathrm{M}$ (Table 1). These results indicate that the inhibition of ICAM-1 expression by the triene-ansamycin group of compounds is closely related to their ability to prevent translation.

Effect of translation inhibitors on ICAM-1 expression induced by TNF- $\alpha$ and IL- $1 \alpha$

The above observation that the triene-ansamycin group compounds inhibited the TNF- $\alpha$-induced ICAM-1 expression more preferentially than the IL- $1 \alpha$-induced ICAM-1 expression prompted us to investigate the effect of other translation inhibitors on ICAM-1

Table 1 Biological activities of triene-ansamycin group of compounds

\begin{tabular}{llll}
\hline & \multicolumn{2}{c}{ ICAM-1 expression } & \\
\cline { 2 - 3 } Compound & TNF- $\alpha$ & IL-1 & \\
\hline Mycotrienin I & 0.57 & 4.9 & Translation \\
Mycotrienin II & 0.3 & 3.1 & 6.2 \\
Trienomycin A & 0.61 & 3.0 & 4.1 \\
13-Ketomycotrienin I & $>10$ & $>10$ & 4.4 \\
13-Ketomycotrienin II & $>10$ & $>10$ & $>10$ \\
Trierixin & 0.16 & 0.62 & $>10$ \\
Quinotrierixin & 0.84 & 4.7 & 2.2 \\
Quinotrierixin HQ & 1.3 & 6.2 & 2.8 \\
Demethyltrienomycinol & $>10$ & $>10$ & 3.7 \\
\hline
\end{tabular}

Abbreviations: ICAM-1, intercellular adhesion molecule-1; IL-1 $\alpha$, interleukin- $1 \alpha$; TNF- $\alpha$, tumor necrosis factor- $\alpha$.

aA549 cells were preincubated with serial dilutions of compounds for $1 \mathrm{~h}$ and then incubated with TNF- $\alpha\left(2.5 \mathrm{ng} \mathrm{ml}^{-1}\right)$ or IL-1 $\alpha\left(0.25 \mathrm{ng} \mathrm{ml}^{-1}\right)$ for $6 \mathrm{~h}$ in the presence or absence of compounds. ICAM-1 expression (\%) was determined by triplicate cultures. The means of $\mathrm{IC}_{50}$ values $(\mu \mathrm{m})$ were calculated from three independent experiments.

bLuciferase mRNA was translated by rabbit reticulocyte lysates in the presence of serial dilutions of compounds at $30^{\circ} \mathrm{C}$ for $90 \mathrm{~min}$. Luciferase activity (\%) was determined by triplicate measurements. The means of $\mathrm{IC}_{50}$ values $(\mu \mathrm{m})$ were calculated from two independent experiments, except for trierixin. expression induced by TNF- $\alpha$ and IL- $1 \alpha$. As reported in our previous paper, ${ }^{14}$ acetoxycycloheximide inhibited the TNF- $\alpha$-induced ICAM-1 expression at much lower concentrations than the IL- $1 \alpha$-induced ICAM-1 expression (Figure 4a), whereas cycloheximide prevented the TNF- $\alpha$ - and IL- $1 \alpha$-induced ICAM-1 expression at relatively similar concentrations (Figure 4b). By contrast, anisomycin inhibited the TNF- $\alpha$-induced ICAM- 1 expression more strongly than the IL- $1 \alpha$ induced ICAM-1 expression (Figure 4c), whereas puromycin and emetine prevented the TNF- $\alpha$ - and IL- $1 \alpha$-induced ICAM- 1 expression at equivalent concentrations (Figures $4 \mathrm{~d}$ and e). These data indicate that the triene-ansamycin group compounds exert inhibitory profiles similar to acetoxycycloheximide and anisomycin.

\section{DISCUSSION}

Cytotrienin A, a structural derivative of mycotrienin II, was initially identified as an inducer of apoptosis. ${ }^{17,18}$ Recently, it has been shown that cytotrienin A inhibits eukaryotic protein synthesis by targeting translation elongation and interfering with eukaryotic elongation factor 1A function. ${ }^{15}$ Consistent with this and our findings, ${ }^{15,16}$ mycotrienin II and its structural derivatives inhibited cellular protein synthesis and cell-free translation. Nevertheless, the de novo protein synthesis in intact living cells (Figure 2a) was inhibited much more strongly by mycotrienin II than the cell-free translation (Table 1). The difference in sensitivity is in agreement with the observation that cytotrienin A inhibits cellular protein synthesis more strongly than the cell-free translation. ${ }^{15}$ This may be because the cell-free translation systems contain larger amounts of proteins that bind to mycotrienin II or cytotrienin A (most likely eukaryotic elongation factor 1A) than living cells, and therefore higher concentrations of the compounds are required for the inhibition of translation.

Nevertheless, the concentrations of mycotrienin II required to inhibit the IL- $1 \alpha$-induced ICAM- 1 expression (Figures $1 \mathrm{~b}$ ) were still higher than those required to inhibit constitutive de novo protein synthesis monitored by $\left[{ }^{3} \mathrm{H}\right] \mathrm{L}$-leucine incorporation (Figure $2 \mathrm{a}$ ). By contrast, we have shown that the protein synthesis inhibitor cycloheximide prevents cellular protein synthesis and IL- $1 \alpha$-induced ICAM-1 expression at
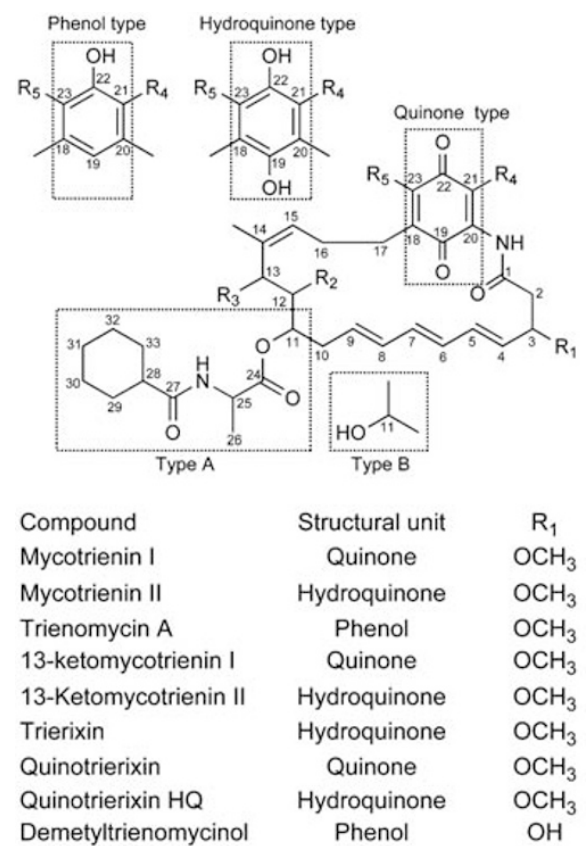

Structural unit
Quinone
Hydroquinone
Phenol
Quinone
Hydroquinone
Hydroquinone
Quinone
Hydroquinone
Phenol

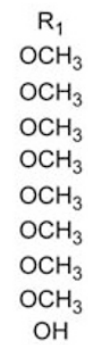

$\begin{array}{cc}\mathrm{R}_{2} & \mathrm{R}_{3} \\ \mathrm{CH}_{3} & \mathrm{OH} \\ \mathrm{CH}_{3} & \mathrm{OH} \\ \mathrm{CH}_{3} & \mathrm{OH} \\ \mathrm{CH}_{3} & =\mathrm{O} \\ \mathrm{CH}_{3} & =\mathrm{O} \\ \mathrm{CH}_{3} & \mathrm{OH} \\ \mathrm{CH}_{3} & \mathrm{OH} \\ \mathrm{CH}_{3} & \mathrm{OH} \\ \mathrm{H} & \mathrm{OH}\end{array}$

$\begin{array}{ccc}\mathrm{R}_{4} & \mathrm{R}_{5} & \text { Side chain } \\ \mathrm{H} & \mathrm{H} & \mathrm{A} \\ \mathrm{H} & \mathrm{H} & \mathrm{A} \\ \mathrm{H} & \mathrm{H} & \mathrm{A} \\ \mathrm{H} & \mathrm{H} & \mathrm{A} \\ \mathrm{H} & \mathrm{H} & \mathrm{A} \\ \mathrm{SCH}_{3} & \mathrm{H} & \mathrm{A} \\ \mathrm{H} & \mathrm{SCH}_{3} & \mathrm{~A} \\ \mathrm{H} & \mathrm{SCH}_{3} & \mathrm{~A} \\ \mathrm{H} & \mathrm{H} & \mathrm{B}\end{array}$

Figure 3 Structures of triene-ansamycin groups of compounds. 

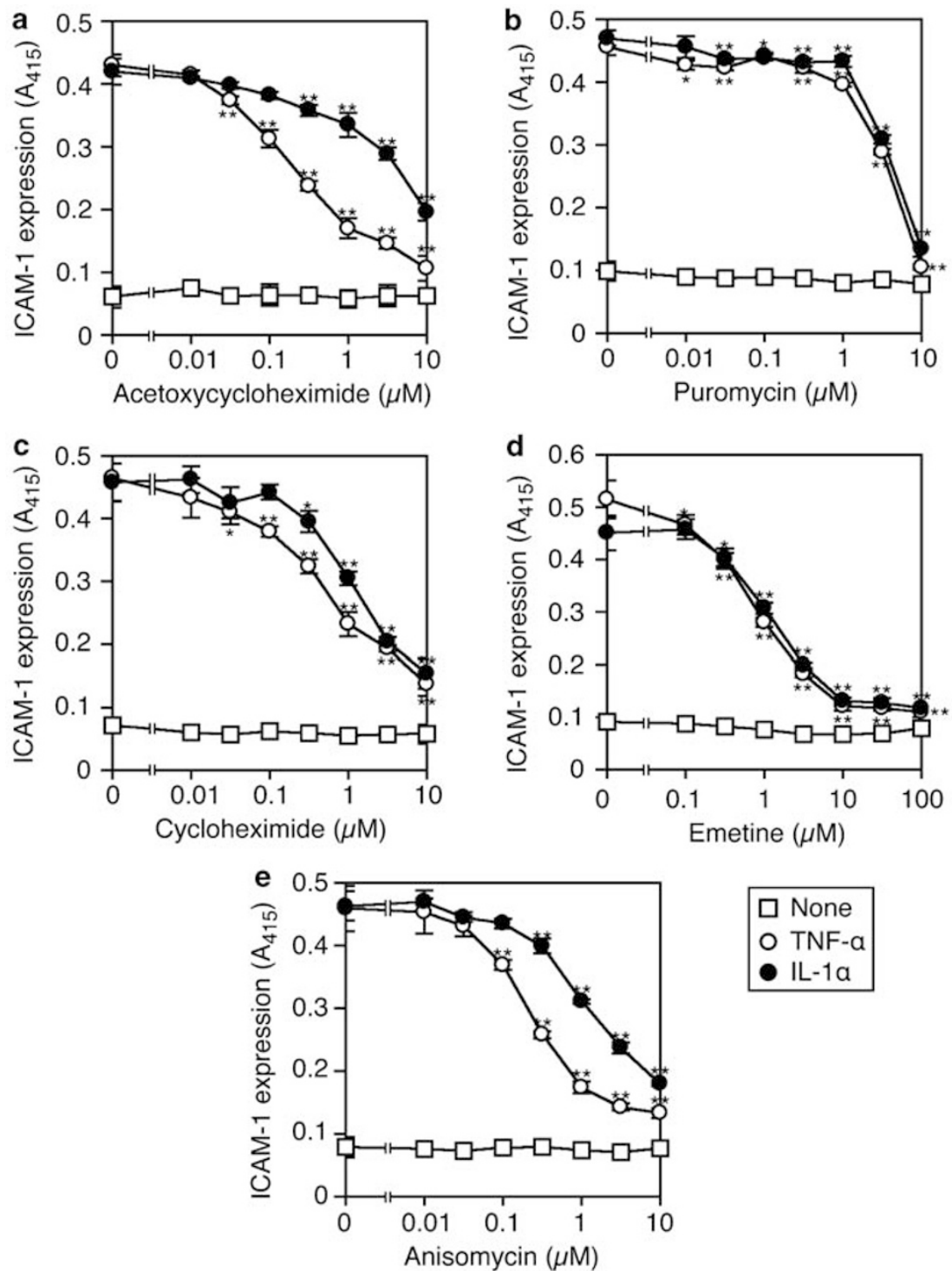

Figure 4 Effect of translation inhibitors on cell-surface intercellular adhesion molecule-1 (ICAM-1) expression induced by tumor necrosis factor- $\alpha$ (TNF- $\alpha$ ) and interleukin-1 $\alpha(\mathrm{IL}-1 \alpha)$. A549 cells were pretreated with various concentrations of acetoxycycloheximide (a), cycloheximide (b), anisomycin (c), puromycin (d) or emetine (e) for $1 \mathrm{~h}$ and then incubated with TNF- $\alpha\left(2.5 \mathrm{ngml}^{-1}\right.$; open circles) or IL- $1 \alpha\left(0.25 \mathrm{ngml}^{-1}\right.$; filled circles) or without cytokines (open squares) for $6 \mathrm{~h}$ in the presence of the compound. ICAM-1 expression $\left(\mathrm{A}_{415}\right)$ is shown as means $\pm \mathrm{s}$. d. $(n=3)$. ${ }^{*} P<0.05$ and ${ }^{* *} P<0.01$, compared with control. Data are representative of two independent experiments.

relatively similar concentrations in A549 cells. ${ }^{14}$ Eukaryotic elongation factor $1 \mathrm{~A}$ is indispensable for the translation of all polypeptide-encoded mRNAs in that it has an essential role in the delivery of the aminoacyltRNA to the ribosome A site and the subsequent GTP hydrolysis. Therefore, the inhibitory effect of mycotrienin II may be influenced by unidentified intracellular factors and/or conditions other than eukaryotic elongation factor $1 \mathrm{~A}$ in intact living cells.

The present structure-activity relationship study demonstrated that the hydroxyl group at $\mathrm{C}-13$ is essential for the inhibitory activities of the triene-ansamycin compounds on ICAM-1 expression, as well as the cell-free translation, whereas the difference in the benzenoid moiety (phenol, hydroquinone and quinone) did not alter the inhibitory activities (Table 1). These properties of the triene-ansamycin group are in agreement with the structure-activity relationship study of the inhibitors of endoplasmic reticulum stress-induced X-box binding protein 1 activation. ${ }^{13}$ In addition, mycotrienin II and its five structural derivatives inhibited the TNF- $\alpha$-induced ICAM-1 expression several times more strongly than the IL- $1 \alpha$-induced ICAM- 1 expression (Table 1). As shown in Figure 3, these characteristic inhibitory profiles were observed with translation inhibitors that potently induce ribotoxic stress response (acetocycloheximide and anisomycin), but not obviously observed with those that induce ribotoxic stress response weakly or not at all (cycloheximide, puromycin and emetine). ${ }^{19-23}$ Ribotoxic stress response caused by translation inhibitors triggers the activation of the mitogen-activated protein kinase superfamily, thereby leading to diverse cellular responses, such as gene expression and apoptosis. ${ }^{19-26}$

Ectodomain shedding is a critical posttranslational mechanism for the regulation of the function of membrane-anchored ligands and receptors. TNF- $\alpha$-converting enzyme cleaves many transmembrane proteins, including TNF- $\alpha$ and TNF receptor 1 (TNF-R1), into their soluble forms and has a regulatory role in TNF- $\alpha$-dependent cellular 
responses. ${ }^{27,28}$ We have previously shown that acetoxycycloheximide induces the ectodomain shedding of TNF-R1 by TNF- $\alpha$-converting enzyme in a manner that is dependent on the activation of extracellular-signal regulated kinase and p38 mitogen-activated protein kinase in A549 cells. ${ }^{22,23}$ Consistently, we observed that mycotrienin II induced the upregulation of soluble extracellular TNF-R1 in A549 cells and that it was prevented by the TNF- $\alpha$-converting enzyme inhibitor TAPI-2 (unpublished data). Thus, mycotrienin II seems to induce the ectodomain shedding of TNF-R1 in a manner similar to acetoxycycloheximide. Because the ectodomain shedding of TNF-R1 by TNF- $\alpha$-converting enzyme weakens responsiveness to TNF- $\alpha$, it seems possible that mycotrienin II is able to trigger activation of the mitogen-activated protein kinase superfamily and thereby induce the ectodomain shedding of TNF-R1, leading to the reduction of TNF- $\alpha$ responsiveness. Ribotoxic stress response possibly induced by the triene-ansamycin group compounds may account for the preferential inhibition of the TNF- $\alpha$-induced ICAM-1 expression rather than the IL- $1 \alpha$-induced ICAM- 1 expression.

\section{ACKNOWLEDGEMENTS}

We are very grateful to Drs. Kazuo Nagai, Yoshinori Tsukumo and Rei Koyanagi for their initial contributions to start this work. This work was supported by a Grant-in-Aid for Scientific Research (KAKENHI) from Japan Society for the Promotion of Science (JSPS) and a Grant-in-Aid from the Naito Foundation.

1 Collins, $T$. et al. Transcriptional regulation of endothelial cell adhesion molecules: NF-KB and cytokine-inducible enhancers. FASEB J. 9, 899-909 (1995).

2 Springer, T. A. Adhesion receptors of the immune system. Nature 346, 425-434 (1990).

3 Springer, T. A. Traffic signals for lymphocyte recirculation and leukocyte emigration: the multistep paradigm. Cell 76, 301-314 (1994).

4 Cook-Mills, J. M. \& Deem, T. L. Active participation of endothelial cells in inflammation. J. Leukoc. Biol. 77, 487-495 (2005).

5 Kataoka, T. Chemical biology of inflammatory cytokine signaling. J. Antibiot. 62, 655667 (2009).

6 Coronelli, C., Pasqualucci, R. C., Thiemann, J. E. \& Tamoni, G. Mycotrienin, a new polyene antibiotic isolated from Streptomyces. J. Antibiot. 20, 329-333 (1967).

7 Sugita, M., Sasaki, T., Furihata, K., Seto, H. \& Otake, N. Studies on mycotrienin antibiotics, a novel class of ansamycins. II. Structure elucidation and biosynthesis of mycotrienins I and II. J. Antibiot. 35, 1467-1473 (1982).

8 Sugita, M. et al. Studies on mycotrienin antibiotics, a novel class of ansamycins. I. Taxonomy, fermentation, isolation and properties of mycotrienin I and II. J. Antibiot. 35, 1460-1466 (1982).

9 Sugita, M. et al. Studies on mycotrienin antibiotics, a novel class of ansamycins. III. The isolation, characterization and structures of mycotrienols I and II. J. Antibiot. 35, 1474-1479 (1982).
10 Sugita, M. et al. Studies on mycotrienin antibiotics, a novel class of ansamycins. IV. Microbial conversion of mycotrienin-II to mycotrienol-II, 34-hydroxymycotrienin-II and 22-0- $\beta$-D-glucopyranosyl mycotrienin-II by Bacillus megaterium. J. Antibiot. 38, 799-802 (1985).

11 Feuerbach, D., Waelchli, R., Fehr, T. \& Feyen, J. H. M. Mycotrienins. A new class of potent inhibitors of osteoclastic bone resorption. J. Biol. Chem. 270, 25949-25955 (1995).

12 Tashiro, E. et al. Trierixin, a novel inhibitor of ER stress-induced XBP1 activation from Streptomyces sp. I. Taxonomy, fermentation, isolation, and biological activities. J. Antibiot. 60, 547-553 (2007).

13 Kawamura, T., Tashiro, E., Yamamoto, K., Shindo, K. \& Imoto, M. SAR study of a novel triene-ansamycin group compound, quinotrierixin, and related compounds, as inhibitors of ER stress-induced XBP1 activation. J. Antibiot. 61, 303-311 (2008).

14 Sugimoto, H. et al. E-73, an acetoxyl analogue of cycloheximide, blocks the tumor necrosis factor-induced NF-kB signaling pathway. Biochem. Biophys. Res. Commun. 277, 330-333 (2000).

15 Lindqvist, L. et al. Inhibition of translation by cytotrienin A-a member of the ansamycin family. RNA 16, 2404-2413 (2010).

16 Yamamoto, K., Tashiro, E. \& Imoto, M. Quinotrierixin inhibits ER stress-induced XBP1 mRNA splicing through inhibition of protein synthesis. Biosci. Biotechnol. Biochem. 75, 284-288 (2011).

17 Kakeya, H. et al. Cytotrienin A, a novel apoptosis inducer in human leukemia HL-60 cells. J. Antibiot. 50, 370-372 (1997).

18 Zhang, H. P., Kakeya, H. \& Osada, H. Novel triene-ansamycins, cytotrienins A and B, inducing apoptosis on human leukemia HL-60. Tetrahedron Lett. 38, 1789-1792 (1997).

19 Iordanov, M. S. et al. Ribotoxic stress response: activation of the stress-activated protein kinase JNK1 by inhibitors of the peptidyl transferase reaction and by sequencespecific RNA damage to the $\alpha$-sarcin/ricin loop in the 28S rRNA. Mol. Cell. Biol. 17, 3373-3381 (1997).

20 Sidhu, J. S. \& Omiecinski, C. J. Protein synthesis inhibitors exhibit a nonspecific effect on phenobarbital-inducible cytochome P450 gene expression in primary rat hepatocytes. J. Biol. Chem. 273, 4769-4775 (1998).

21 Shifrin, V. I. \& Anderson, P. Trichothecene mycotoxins trigger a ribotoxic stress response that activates $\mathrm{C}$-Jun $\mathrm{N}$-terminal kinase and p38 mitogen-activated protein kinase and induces apoptosis. J. Biol. Chem. 274, 13985-13992 (1999).

22 Ogura, $\mathrm{H}$. et al. Ectodomain shedding of TNF receptor 1 induced by protein synthesis inhibitors regulates TNF- $\alpha$-mediated activation of NF- $\mathrm{kB}$ and caspase-8. Exp. Cell Res. 314, 1406-1414 (2008).

23 Ogura, $\mathrm{H}$. et al. ERK and p38 MAP kinase are involved in downregulation of cell surface TNF receptor 1 induced by acetoxycycloheximide. Inter. Immunopharmacol. 8, 922-926 (2008).

24 Kadohara, K. et al. Acetoxycycloheximide (E-73) rapidly induces apoptosis mediated by the release of cytochrome $c$ via activation of c-Jun $\mathrm{N}$-terminal kinase. Biochem. Pharmacol. 69, 551-560 (2005).

25 Kadohara, K. et al. Caspase-8 mediates mitochondrial release of pro-apoptotic proteins in a manner independent of its proteolytic activity in apoptosis induced by the protein synthesis inhibitor acetoxycycloheximide in human leukemia Jurkat cells. J. Biol. Chem. 284, 5478-5487 (2009).

26 Chinen, T. et al. Irciniastatin A induces JNK activation that is involved in caspase-8-dependent apoptosis via the mitochondrial pathway. Toxicol. Lett. 199, 341-346 (2010).

27 Schlöndorff, J. \& Blobel, C. P. Metalloprotease-disintegrins: modular proteins capable of promoting cell-cell interactions and triggering signals by protein-ectodomain shedding. J. Cell Sci. 112, 3603-3617 (1999).

28 Moss, M. L., White, J. M., Lambert, M. H. \& Andrews, R. C TACE and other ADAM proteases as targets for drug discovery. Drug Discov. Today 6, 417-426 (2001). 